\title{
Does trust extend beyond the village? \\ Experimental trust and social distance in Cameroon
}

\author{
Alvin Etang, David Fielding, Stephen Knowles
}

Address for correspondence:

Alvin Etang

Department of Economics

University of Otago

PO Box 56

Dunedin 9054

NEW ZEALAND

E-mail: alvin.etang@otago.ac.nz

Telephone: 6434798654

Fax: 6434798174 


\begin{abstract}
In this paper we use experimental data collected in rural Cameroon to quantify the effect of social distance on trust and altruism. Our measure of social distance is one that is relevant to everyday economic interactions: subjects in a Trust Game play with fellow villagers or with someone from a different village. We find that Senders in a Trust Game pass significantly more money to Recipients from their own village than to Recipients from a different village. To test for the possibility that Senders are motivated by unconditional kindness, they also play a Triple Dictator Game. We find that Senders pass significantly more money on average in the Trust Game than in the Triple Dictator Game, confirming that transfers in the Trust Game are partly motivated by Trust. However, there is also a social distance effect in the Triple Dictator Game, and around one third of the social distance effect in the Trust Game is due to greater unconditional kindness to fellow villagers. Results from a Risk Game suggest that Trust Game transfers are uncorrelated with attitudes to risk.
\end{abstract}

Keywords Experiment $\bullet$ Trust Game • Dictator Game • Risk Game • Social distance $\bullet$ Cameroon

JEL Classification C93 • O $12 \bullet \mathrm{Z} 13$ 


\section{Introduction}

Fukuyama (1995) suggests that people are more likely to trust people with whom they interact regularly. In other words, trust is likely to decrease with social distance, or the "radius of trust". The extent to which the radius of trust diminishes is important from a policy perspective: if people only trust those with whom they interact regularly then the size of the market is limited, reducing opportunities for economic gain. There are a few papers in the literature which use an economic experiment known as the Trust Game, to test the extent to which the degree of trust diminishes with social distance. However, most of these experiments are conducted on university students, who may not be representative of the rest of the population.

Although most Trust Game experiments take place in Europe or North America, questions relating to trust are particularly relevant to Africa, where there appears to be a marked lack of trust. In the World Values Survey for 1999-2002, $35 \%$ of North America and Western European respondents answered in the affirmative to the question, "Generally speaking, would you say that most people can be trusted?" The corresponding figure for the rest of the world (excluding Africa) is $26 \%$; for Africa it is only $19 \%$. Survey data from several different parts of Africa indicate that trust is a necessary condition for the development of private sector economic activity beyond the village level (Lyon, 2000; Trager, 1981).

In this paper, residents from two different villages in rural South-West Cameroon take part in the Trust Game, with some participants playing against people from their own village and others playing against people from the other village. To our knowledge, our study is the first to use experimental data to analyse the extent to which trust in fellow villagers exceeds trust in those from a nearby village. As we explain below, participants commonly engage in economic transactions with both fellow villagers and people from the other village, but social distance for inter-village transactions is much larger. Our measure of social distance is therefore much more closely aligned with real-world economic activity than in many other experimental studies, especially those using university undergraduates. Moreover, given the very limited geographical mobility in this part of Cameroon, village membership can reasonably be regarded as a treatment effect. We also test for the possibility that transfers in the Trust Game are 
motivated not just by trust, but also by unconditional kindness or risk aversion by having participants play a Triple Dictator Game and a Risk Game. This also allows us to analyse the extent to which generosity and risk aversion decreases with social distance.

Our empirical results suggest that participants are more trusting of, and behave more generously towards, those from their own village than those from another village. However, the level of trust in, and generosity towards, those in the other village is still quite high, even though most villagers have relatively little contact with the other village. We also find that Trust Game transfers can be partly (but not fully) explained by unconditional kindness, as measured by the Triple Dictator Game. However, there is no correlation between Trust Game transfers and attitudes to risk.

The remainder of the paper is organised as follows. Section 2 reviews the relevant literature on the Trust Game, focusing on studies which analyse how trust diminishes with social distance. Section 3 provides some background information on the villages where the field work was conducted, and provides details of our experimental methodology. Section 4 discusses our empirical findings, with Section 5 concluding.

\section{Literature review}

The Trust Game was introduced into the experimental economics literature by Berg et al. (1995). Since then it has been conducted in a number of countries to test various hypotheses about the determinants of trust and the effects of trust on other variables. In the Trust Game players are divided into two groups: Senders (A Players) and Recipients (B Players). Each Sender is paired with a Recipient, but typically the players do not know the identity of the person with whom they are paired. Each Sender is then given a sum of money (for example ten dollars) and has to decide how much money, if any, to transfer to the Recipient. Any money transferred is tripled by the experimenter, and the Recipient then has to decide how much of the money, if any, to return to the Sender. The Sender will be better off if the Recipient returns more than a third of the money transferred. However, for the Sender to transfer any money requires trusting that a significant proportion of the money will be returned. Hence, the amount of money sent is 
interpreted as how trusting the Sender is of the anonymous Recipient, and the amount returned is interpreted as indicating how trustworthy the Recipient is (or, in other words, the extent to which the Recipient reciprocates the Sender's trust). Readers interested in a detailed review of results from the Trust Game are referred to Chaudhuri (2009) and Cardenas and Carpenter (2008). In reviewing the past literature on the Trust Game, we restrict our focus to studies that have used the Trust Game to measure the extent to which the amounts sent and returned diminish with the degree of social distance between players.

A small number of studies in the literature use an inter-country design in which some university students are paired with students from their own university, while others are paired with students from a university in a different country. Each participant plays with only one other participant, and comparisons are made in the behavior of different players under different treatments; this is a between-subjects design. Netzer and Sutter (2009) find that Austrian students in a Trust Game send more to Japanese students than to Austrian students, but the amount sent by Japanese students is invariant to the nationality of the recipient. Willinger et al. (2003) also find that French and German students' levels of trust and trustworthiness are invariant to whether the other participant in the game is French or German. Walkowitz et al. (2003) play the Trust Game with students from three countries: Germany, China and Argentina. Their study is different in that it uses a within-subjects design: each participant plays with a student from her own country and with foreign students. In general, players' behavior is independent of the nationality of their partner, except that Chinese Recipients return less money to Argentinean players than to Chinese or German players. If trust does decline with social distance then we would expect the amount sent to compatriots to be higher. These studies show little or no evidence of a social distance effect.

A similar methodology is used by Fershtman and Gneezy (2001), who play the Trust Game in Israel with two ethnic groups: Ashkenazic Jews and Eastern Jews. Participants are drawn from two different universities. All participants are paired with someone from the other university: some participants are paired with someone from their own ethnic group, and others are paired with someone from the other ethnic group. Participants are told the name of the person with whom they are paired, from which they can infer the other player's ethnicity. 
The average amount of money sent to Ashkenazic players is significantly higher than that sent to Eastern players, irrespective of the ethnicity of the Sender. This indicates an ethnicity effect rather than a social distance effect. Separate groups of players also take part in a Triple Dictator Game (a game where the second stage of the Trust Game is omitted). ${ }^{1}$ There is little evidence of a correlation between the size of the Triple Dictator Game donations and the ethnicity of the Recipient.

There are a handful of studies which find common membership of a certain type of group to increase experimental trust. These can be interpreted in terms of a social distance effect, but with the caveat that group membership could be a treatment effect (joining the group leads people to trust each other) or a selection effect (people who trust each other join the group). Using Trust Game experiments in Peru, Karlan (2005) finds that membership of the same church is correlated with experimental trust, but membership of the same credit group is not. Etang et al. (2007) find a positive correlation between membership of the same Rotating Savings and Credit Association (ROSCA) and the amounts sent and returned in the Trust Game by inhabitants of a single Cameroonian village. Cadsby et al. (2008) play the Trust Game with Chinese university students, some of whom play against their class mates and others against those from another class. They find that more trusting behavior is exhibited towards between classmates, than towards those from another class. ${ }^{2}$

In order to rule out the possibility of a selection effect and ensure that common group membership is a genuine treatment, Buchan et al. (2006) randomly assign people to artificially created groups. They use a sample of university students in China, Japan, Korea and the United States. Although this study involves students from different countries, students only play against those from their own country. Before playing the Trust Game, participants spend ten

\footnotetext{
${ }^{1}$ More details on the Triple Dictator Game are provided in Section 3 below.

${ }^{2}$ A few studies have examined whether the number of voluntary organizations someone belongs to is positively correlated with the amount sent or returned in the Trust Game. For example, Mosley and Verschoor (2005) find that group membership is positively correlated with both the amount sent and the amount returned in the Trust Game in rural Uganda. However, Ashraf et al. (2006) (Russian, South African and US data), Carter and Castillo (2003) (South African data) and Johansson-Stenman et al. (2006) (Bangladeshi data) find no evidence of any such correlation. These studies do not compare intra-group transfers with inter-group transfers, so they do not address questions about social distance directly.
} 
minutes in groups introducing themselves to each other. When the Trust Game is played, participants are told if they are playing against someone from their discussion group (the in-group) or someone from a different group (the outgroup). The effect of this experimentally generated social distance on behavior differs by country. Americans send (and return) more money to in-group members, but Chinese students send (and return) more to out-group members; social distance has little effect on behavior in Japan and Korea.

Buchan and Croson (2004) take a novel approach to measuring the effects of social distance on trust using both a Trust Game and survey data with a sample of students from China and the United States. As in Buchan et al. (2006), Senders are always paired with Recipients from the same university. Participants first play a standard Trust Game. After the Senders have made their transfers, but before they find out how much money they have received back, they complete a questionnaire. This questionnaire asks, hypothetically, how much money they would send, and how much they would expect to receive back, if they were to play the game against seven different types of player with varying degrees of social distance: a parent, a sibling, a cousin, a student they know well, a student from another university, a stranger from their home town and a stranger from another country. Recipients are also asked how much money they would expect to receive from, and how much they would send back to, Senders from each of the seven groups. In both the United States and China, the hypothetical amounts sent and returned tend to fall as social distance increases. In both countries, the average amount hypothetically sent to parents is close to 100 percent, while the amount hypothetically sent to a stranger in another country is just over 40 percent. The benefit of this approach is that data are obtained for many different points on the radius of trust without having to play the game more than once with each player. However, the data are essentially survey-based rather than experimental, since participants do not actually play the Trust Game against all of the different groups.

Another way to measure the effect of social distance on trust is to let players know the identity of the person with whom they are paired. This enables researchers to test whether the amount of social distance between players is correlated with how they play the Trust Game. However, the loss of anonymity does mean that players' decisions may be influenced by the fear of reprisal if they 
do not play according to their partner's expectations. Glaeser et al. (2000) use this approach with Harvard undergraduates, finding that the amount sent and proportion returned both increase with the number of months the players have known each other. The amount sent is not affected by whether the players are compatriots, but the proportion returned is lower when players are from different countries. Players paired with someone from a different racial group are likely to return a lower proportion of money, but common ethnicity has no effect on the amount sent.

The results obtained from these can be summarised as follows. In the inter-country and inter-ethnic studies, players' decisions are invariant to whether the players are from the same country. Sometimes, a particular ethnic group or nationality appears to be regarded as more trustworthy by all groups, including those outside the group, but this is hardly a social distance effect. Other types of study do often find a social distance effect. In Buchan et al (2006) social distance matters in some countries but not in others. Buchan and Croson (2004) make a useful contribution to the literature, but their data on social distance are based on how participants say they would play the game, not on how they actually play the game. Glaeser et al. (2000) find that trust and trustworthiness do decline with some forms of social distance, but the lack of anonymity limits the interpretation of their results.

With the exception of Karlan (2005) and Etang et al. (2007), all of the studies summarised above have been conducted on university students, who may not be representative of the rest of the population. Very often, the students are paired with people with whom they could not reasonably expect to have a realworld economic transaction. Inter-country studies are potentially relevant to important international social and political questions, but are more difficult to relate directly to a specific economic context. Although some studies have analysed whether people are less trusting of those from other countries or ethnic groups, there are no anonymised experimental studies analysing the effect of social distance among people of the same nationality and ethnic group. This level of social distance - comparing, for example, trust within a village to trust between neighbouring villages - is highly relevant to questions about the link between trust and market efficiency or market size. There are some studies in which participants are drawn from different villages in developing countries, but we know of no 
cases in which some participants play against fellow villagers and others play against those from a different village. ${ }^{3}$

Although the Trust Game is normally interpreted as measuring trust, the amount of money sent in the Trust Game could be influenced by at least two other factors. The first is that in some cases the Sender's utility is a positive function of the Recipient's utility. In other words, some people may simply be more generous. We refer to this possibility as "unconditional kindness". The second is that some people may send less because they are more risk averse. This possibility is explicitly acknowledged (but not tested) by Cadsby et al. (2008), and by Buchan et al. (2006), who refer to the Trust Game by its original name, the "Investment Game", interpreting the results as being informative about "other regarding preferences”. Fershtman and Gneezy (2001) test for the possibility that unconditional kindess may be important by playing a Triple Dictator Game as well as a Trust Game.

This paper explores whether trust and trustworthiness decline as social distance increases from interaction with fellow villagers to interaction with people from a neighbouring village. We test this by conducting a Trust Game, using a between-subjects design, in rural Cameroon. Our sample of Cameroonian villagers differs greatly from those used in previous studies on trust and social distance, nearly all of which rely on university students. In addition, we test for the possibility that behavior in the Trust Game is influenced not just by trust, but by unconditional kindness and risk aversion.

\section{Experimental design}

The Trust Game was outlined in Section 2. As noted above, the amount of money sent in the Trust Game may depend on unconditional kindness and the extent of risk aversion, as well as trust. To control for this possibility, we had Senders in the Trust Game (A Players) also play a Triple Dictator Game and a Risk Game. The amount returned in the Trust Game may also depend on unconditional kindness, but not on risk, as the Recipient already knows what the Sender's decision is. We

\footnotetext{
${ }^{3}$ In Barr (2003) and Schechter (2007), players are drawn from different villages, but all are paired with fellow villagers. In Johansson-Stenman et al. (2006), players are always paired with someone from a different village.
} 
therefore had Recipients in the Trust Game (B Players) play a Standard Dictator Game, but not a Risk Game. For the remainder of the paper we use the phrase "pure trust" to describe Trust Game transfers that are not due to unconditional kindness (as measured by the Triple Dictator Game) or risk (as measured by the Risk Game).

The Triple Dictator Game is identical to the first phase of the Trust Game, in that the Sender is given an endowment and told that the amount transferred to the Recipient will be tripled. However, the Recipient cannot return any money to the Sender, which rules out trust as a motive for sending money. Instead, Senders may transfer money due to unconditional kindness, with no expectation of receiving anything in return. Previous studies in which Senders have played both a Trust Game and a Triple Dictator Game include Ashraf et al. (2006) and Cox (2004). In the Standard Dictator Game, the amount sent is not tripled. For a Player $\mathrm{B}$, this game will capture the extent to which transfers back to Player A in the Trust Game (which are not multiplied by the experimenter) are motivated by unconditional kindness.

Our Risk Game, played by A Players only, is based on Schechter (2007), who plays both a Trust Game and a Risk Game (but not a Triple Dictator Game) in rural Paraguay. In our study, each Player A is given the option of investing all, some or none of an initial endowment in a hypothetical risky project, the payoff from which is determined by the roll of a dice. If the experimenter rolls a one then the player loses her investment; if a two is rolled then the Player receives back half of the money invested; if a three is rolled then the player receives the amount invested; if a four is rolled then the payoff is 1.5 times the amount invested; if a five is rolled then the payoff is double the investment; if a six is rolled then the payoff is three times the investment. Any money not invested is kept by the player. The maximum and minimum possible returns are therefore the same as for the Trust Game.

The field work was carried out in November 2008, in two villages in the South West Province of Cameroon, a poor but stable African country which has never had a civil war. For the remainder of the paper we refer to the two villages as Village 1 and Village 2. ${ }^{4}$ The population of Village 1 has approximately 1,000 inhabitants and Village 2 approximately 1,500 inhabitants. The distance between

\footnotetext{
${ }^{4}$ The anonymity of the villages was a condition for university ethical approval of this research.
} 
the two villages is about $10 \mathrm{~km}$. Another, larger village is located between Village 1 and Village 2. The most common place for people from the three different villages to meet each other is the market in the larger, middle village. Here, peasant farmers (the majority of the local population) buy and sell food, and local traders sell clothes and hardware brought from the nearest town, which is about $40 \mathrm{~km}$ away from Village 1 and $30 \mathrm{~km}$ away from Village 2. The villages are connected to each other and to the town by dirt tracks; most villagers travel by foot or bicycle. As shown in Table 1 below, only a few participants had friends or family in the other village, but all participants had visited the other village at least once in their life. In both villages, agriculture is the main economic activity: coffee and cocoa are the most important crops. Most people have some primary education, but a substantial minority are illiterate. Everyone across the two villages belongs to the same ethnic group and speaks the same language. Social ties within each village are very strong, reinforced by church attendance, reciprocal help with harvests and intermarriage.

Participants were recruited at meetings in each of the two small villages. Those who agreed to participate were told a day and a time to turn up to take part in the experiments. A total of 280 people participated in the study, with 140 from each village. The demographic characteristics of the sample are summarised in Table 1 . The sample is made up of roughly equal numbers of men and women; the average age of participants is just over 40 years. This is substantially greater than the average age in the village, because we only permitted adults to take part in the experiments. The vast majority of the sample (87.5\%) are married. The average number of years lived in the participant's current village is 34.5 , which is only a few years less than the average age of the participants, so most villagers have lived in their current village for all or most of their life. Only $4.3 \%$ of the sample have ever lived in the other village; this is a characteristic that we control for in interpreting our results, but the low percentage reflects the very limited degree of geographical mobility in the area. Most people are born, live and die in the same village, and for the vast majority of our participants village membership can be regarded as a treatment effect. $45 \%$ of the sample belong to ROSCAs, and just over two-thirds have a First School Leaving Certificate (the basic primary education qualification, designated by "education" in the table). Average annual 
income is approximately $660,000 \mathrm{CFA}$, which at the time of the experiment was worth about $\$ 1,500$ US dollars.

\section{[Table 1 about here]}

The data also show that for most people social interactions between the two villages are limited. The average number of friends or relatives a participant has in the other village is 0.3 , so participants playing with someone from the other village knew that the chances of being paired with someone known to them personally were very small. Only $4.3 \%$ of the participants had ever lived in the other village. Although all participants had visited the other village, $84.6 \%$ rarely went there.

The field work was carried out by one of the authors and two locally recruited research assistants. Each participant took part in the experiments in their own village, with the experimenter and two research assistants travelling from village to village. The field work began in Village 1, with the A Players. When players arrived, they were randomly assigned an ID number, which determined who they were paired with. Players were told whether they were paired with someone from their own village or someone from the other village. The same pairings were used for both the Trust Game and the Triple Dictator Game. (The sequencing of games is potentially important, and is described below.) The experimenter explained the rules of the Trust, Dictator and Risk Games to the group verbally, and explained that all payouts would be made in seven days time, when the experimenter would return to the village. Players were told that their initial endowment for each game was 800 CFA francs. At the time of experiment, 800 CFA francs was slightly less than US\$2 - about half a day's wage for most villagers - and could buy just over $1.5 \mathrm{~kg}$ of rice. Players were permitted to make transfers in $100 \mathrm{CFA}$ franc units, so our experimental data have a discrete distribution. The Appendix contains the forms used in the verbal explanation to participants, and outlines the examples used to test participants' understanding during the explanation.

Having explained the rules, the experimenter left for another room. All players were then asked to go in turn to the room occupied by the experimenter, to say how much money they wished to transfer to the player with whom they were anonymously paired for both the Trust Game and the Triple Dictator Game, and 
how much money they wished to invest in the Risk Game. Half of the participants were first asked how much they wished to transfer in the Trust Game, with the other half being first asked how much they wanted to transfer in the Triple Dictator Game. The experimenter then rolled a dice so the player could learn how much money he/she earned in the Risk Game. However, no payouts were made for any of the games at this point. Two research assistants remained in the room with the other players to make sure that they did not discuss how they intended to play the game. After participants had made their decisions in each of the games, they answered questions about they had chosen to transfer any money or not. They then answered a questionnaire asking about demographic characteristics, as well as a range of questions regarding trust and cooperation. This phase of the field work took two days. All of the forms used to record the subjects' decisions in these games and their stated motives appear in the Appendix, as does the questionnaire. These forms were used by the experimenters in their verbal communication with the participants; the forms were completed by the experimenters, not the participants, some of whom were illiterate.

The field work then moved to Village 2, where B Players took on the role of Recipients in the Trust Game and Senders in the Dictator Game. Again, the rules of both games were explained to the participants in a group; the participants were then asked to join the experimenter one at a time in a separate room. They were asked how much they wanted to transfer in the Dictator Game. They were then told how much money had been transferred to them in the Trust Game, and were asked how much money they wished to return. All B Players played the Dictator Game before being told how much they had received in the Trust Game. In separate sessions in Village 2, the A Players took part in the experiments, following the same protocol as had players in Village 1. This phase of the field work took three days.

The experimenter and research assistants then returned to Village 1, where the B Players took part in the experiments. This took one day. For the next seven days the experimenter met with the players who had taken part in the experiments a week previously, and paid them whatever sum of money they had earned from the games.

Two potential issues with our experimental design require further discussion. The first is that players had to wait seven days to receive their 
payments, so there may be a concern that their decisions could have depended on how much they trusted the experimenter. However, this concern is mitigated by the fact that players did not receive any money, including the money they chose not to transfer, for seven days. Another potential concern is that players had to tell the experimenter how much money they wished to transfer, rather than being able to record this anonymously, which may have affected their behavior. However, given that many of the participants are illiterate, written transfers were infeasible. The face-to-face nature of the experiment also meant that the experimenter was able to answer any questions the players wanted to ask in private. This face-toface methodology is typically used when dealing with players who are illiterate (Barr, 2003; Karlan, 2005; Schechter 2007).

\section{Results}

\subsection{Descriptive statistics}

In this section we analyse players' behavior in the different games. We begin by presenting descriptive statistics summarising the players' decisions. More formal multivariate regressions analysis is presented in Section 4.2. Throughout the discussion we are interested in two main research questions: (1) do people send (and return) more money in the Trust Game when paired with someone from their own village than with someone from a different village, and (2) can Trust Game transfers be explained, in part, by unconditional kindness (as proxied by the Dictator Games) or risk aversion (as proxied by the Risk Game).

\subsubsection{Amounts sent and returned in the Trust Game}

The results for the amounts sent in the Trust game are summarised in Figure 1. The average amount sent by all A Players, irrespective of whether they were paired with someone from the same village or not was $68.6 \%$. Only one player sent nothing, and he/she was paired with someone from the other village. Figure 1 shows that A Players were more likely to send money if paired with someone from the same village. With intra-village pairs the average amount sent was 74.1\%; with inter-village pairs the average amount sent was 63.2\%. A MannWhitney test indicates this difference in unconditional means to be statistically significant. Trust does appear to decrease with social distance, by a modest amount, but overall trust levels are quite high compared with previous studies. 
Most players rarely visit the other village and do not know anyone there personally, so trusting someone from the other village is equivalent to trust in strangers. Trust in strangers, at least for this part of rural Africa, is high. ${ }^{5}$

\section{[Figure 1 about here]}

The behavior of B Players is shown in Figure 2. No B Player returned less than $33 \%$ of the amount sent, even if paired with someone from the other village. Hence all A Players received back at least as much as they were sent, and the vast majority of A Players were better off as a result of transferring money. In other words, their trust was reciprocated. The mean proportion returned across the whole sample was $46.7 \%$, with a high proportion returning exactly half of what they were sent. The average amount returned was $48.1 \%$ for intra-village pairs and $46.7 \%$ for inter-village pairs; this difference is statistically insignificant. Although A Players were less trusting of players from the other village, B Players were no less trustworthy when paired with someone from the other village. It could be that B Players were more interested in how much they were sent, rather than whether it was sent by someone from their own village. This possibility will be explored in Section 4.2 below.

\section{[Figure 2 about here]}

\subsubsection{Motives for sending and returning money in the Trust Game}

In order to gain insight into why players behaved in the way they did, we included a question in the questionnaire asking participants why they had, or had not, sent or returned money. Recall that the questionnaire was administered after players had made their decisions. This approach follows a number of other studies that question players about their motives, and the questions used were identical to ones appearing in Johansson-Stenman et al. (2006). Players were given three possible answers to choose from: (1) "it would be unfair not to send anything", (2) "the receiver (or sender) probably needs the money more than I do", and (3) "other,

\footnotetext{
${ }^{5}$ Also of interest is the fact that Players from Village 1 sent similar amounts to those from Village 2. The mean amount sent by Players from Village 1 was $69 \%$, with Players from Village 2 sending $68 \%$. This difference is statistically insignificant.
} 
please specify". We coded the first two responses as the "fairness motive" and the "need motive", respectively. Those who chose the "other" option gave several reasons for transferring money. We have separated these open-ended responses into three categories: the "trust motive" (Senders only), the "rewarding trust motive" (Recipients only) and the "equality motive". Responses classified as trust motives were those that explicitly recognized the importance of trust in maximizing the size of the total payoff. For example, the following types of response were coded as the trust motive: "I would earn more by sending more", "it pays to trust" and "he or she may return more than what I sent". Examples of responses under the rewarding trust category include "the person trusted me", "he or she is a good person, because they could have chosen to keep all the money for themselves" and "the individual has confidence in me". Examples of responses coded as the equality motive include "equal sharing of what I have" and "dividing equally".

The most common reason given for transferring money $(48.2 \%)$ was the fairness motive. The trust motive was the next most common $(28.1 \%)$, followed by the need motive (19.4\%) and then the equality motive $(4.3 \%)$ : trust was not the most common motive stated for transferring money. The extent to which Trust Game transfers can be explained by players' stated motives for transferring money will be analysed in Section 4.2 below.

We turn now to the proportion of money returned by the B Players. $82.7 \%$ of B Players state fairness as their motive for returning money. Only two recipients $(1.4 \%)$ stated that they sent money back due to the need motive and only $4.3 \%$ stated that they returned money to reward the trusting behavior of the senders. Finally, $11.5 \%$ reported that they decided to send back money because they wanted to share it equally with the senders. Very few players explicitly stated that they sent money back because they were rewarding trust, but this is a reasonably similar notion to returning money for reasons of fairness, which was by far the most common response.

\subsubsection{Dictator and Risk Game results}

Our main motive for having A Players play a Triple Dictator Game was to test whether they send money in the Trust Game because of unconditional kindness. If this is the case, we would expect similar amounts to be sent in the Trust Game and 
in the Triple Dictator Game. The connection between Trust Game and Triple Dictator Game results is analysed formally in Section 4.2 below. At this point, we simply present some summary data on the amounts sent in the Triple Dictator Game. The distribution of transfers can be seen in Figure 3. The mean transfer across all players was $43.6 \%$; for intra-village transfers the mean was $45.7 \%$ and for inter-village transfers it was $41.4 \%$. This difference in unconditional means is insignificant on the basis of a Mann-Whitney test. The fact that some money was sent in the Triple Dictator Game suggests that the anticipation of reward was not the only motive for sending money in the Trust Game. However, the mean amount sent in the Triple Dictator Game is substantially less than that sent in the Trust Game, which suggests that unconditional kindness was not the only motive for sending money in the Trust Game.

\section{[Figure 3 about here.]}

The B Players played a Standard Dictator Game rather than a Triple Dictator Game. Dictator Game donations should reflect the extent to which transfers in the Trust Game were motivated by unconditional kindness rather than reciprocity. The distribution of B Player transfers in the Standard Dictator Game is shown in Figure 4 . Note that $61 \%$ of players sent half of their endowment, which may imply that transfers are driven by inequality aversion. The mean transfer was $44.4 \%$ for all players, with a mean of $45.7 \%$ for intra-village transfers and $43.0 \%$ for inter-village transfers. This difference is statistically significant at the $5 \%$ level in a Mann-Whitney test. The mean transfer in the Standard Dictator Game is not much lower than the mean amount returned in the Trust Game, suggesting a large proportion of the amount returned in the Trust Game may reflect unconditional kindness rather than reciprocity. This hypothesis will be formally tested using regression analysis in Section 4.2 below.

\section{[Figure 4 about here]}

The amount sent in the Trust Game might also be determined by the players' attitudes to risk, rather than pure trust. The distribution of Risk Game investments is shown in Figure 5. The mean amount invested in the Risk Game is $65.4 \%$. Very few players (1.4\%) invested nothing, with a reasonable number (17.1\%) investing all of their endowment and $84.3 \%$ investing at least half of their endowment. 
Participants do not seem to be particularly risk averse. Given that the Risk Game does not perfectly mimic any particular stage of the Trust Game, little can be inferred directly from comparisons between mean Trust Game donations and mean Risk Game investments. The key question is whether or not Trust Game donations and Risk Game investments are correlated; we analyse this question in Section 4.2.

The descriptive statistics show that players who were paired with someone from their own village sent more money on average in the Trust Game than did players who were paired with someone from a different village. However, the difference in means was not enormous. Whether players were paired with someone from their own village made no statistically significant difference to the amounts returned. Average Trust Game donations were higher than the average Triple Dictator Game donations, suggesting that Trust Game transfers are partially motivated by pure trust. However, Triple Dictator Game transfers were positive. This implies that Trust Game transfers are partially motivated by unconditional kindness. In the next section we use regression techniques to analyse more formally the determinants of the amounts sent and returned in the Trust Game. As well as analysing the extent to which these transfers can be explained by behavior in the Dictator and Risk Games, we also control for the stated motives for sending money and a range of demographic control variables.

\subsection{Formal econometric analysis}

\subsubsection{Amounts sent in the Trust Game}

In this section of the paper we analyse the determinants of the amount sent and proportion returned in the Trust Game using multiple regression analysis. This allows us to control for a range of variables that may affect behavior in the Trust Game. We begin with an analysis of the amount sent, the results for which are reported in Table 2. The dependent variable has a discrete distribution, so we fit the model using a Negative Binomial regression. ${ }^{6}$ The coefficients in the table are

\footnotetext{
${ }^{6}$ The Negative Binomial regression model is a generalisation of the Poisson regression model, the Poisson distribution being replaced by a less restrictive distribution in which the mean and variance need not be equal. The parameter that scales the variance relative to the mean $(\alpha)$ is reported in the tables below for each different regression; it is always statistically significant, indicating that an ordinary Poisson regression is overly restrictive. A linear estimator such as OLS
} 
therefore to be interpreted as the proportional change in the amount sent that can be expected with a unit change in the explanatory variable. Our baseline results are reported in Column (1), where we model the amount sent as a function of a range of demographic variables that have been found to be significant in explaining Trust Game transfers in previous empirical work (for example Schechter, 2007; Johansson-Stenman et al., 2006). These variables include age, income, household size, the number of children and number of years lived in the village, and dummies for gender, martial status (never married, divorced, widowed, with married as the omitted category), whether the participant has ever lived in an urban area, and completion of education. We also include the number of friends the participant has in the other village and a dummy variable for whether the participant has ever lived in the other village, both interacted with a dummy variable for participants playing with someone from the other village.

One additional conditioning variable used in the regressions is a dummy variable for participants who are members of a Rotating Savings and Credit Association (ROSCA). A significant proportion of villagers in rural Cameroon do belong to ROSCAs (45\% in our sample), and Etang et al. (2007) find ROSCA membership to be positively correlated with Trust Game transfers. Such a positive correlation has two possible interpretations. The first is that more trusting people are likely to join ROSCAs (selection effect); the second is that belonging to a ROSCA makes people more trusting (treatment effect). An additional control for the latter is the number of years of ROSCA membership. ${ }^{7}$

\section{[Table 2 about here]}

Our baseline regression is reported in Column (1) of Table 2, in which we do not control for whether players were paired with someone from their own village or someone from the other village. A number of the explanatory variables are

neglects the fact that our dependent variable is comprised entirely of nonnegative integers. Such an estimator can result in biased or inconsistent parameter estimates and lead to invalid inferences (Gourieroux et al., 1984; Mullahy, 1986; Winkelmann, 1997).

${ }^{7}$ Other variables excluded from all reported regressions due to their statistical insignificance are: dummy variables for each experimental session, a dummy variable for whether the Trust Game was played before the Triple Dictator Game, a dummy variable for whether the participant is from Village 1, age squared. 
statistically significant in explaining the amount sent. Men send $14.3 \%$ less money than women on average. People who are divorced (only $3.2 \%$ of the sample) send 31.6\% less. People who have lived in their village for longer send more money, with each additional ten years lived in the village being associated with a $7.9 \%$ increase in transfers. (This effect applies to both intra-village transfers and inter-village transfers. When we interact years lived in the village with the same-village dummy described in the next paragraph, the interaction is statistically insignificant: years lived in the village appears to reflect socialisation within the locality rather than within a particular village.) ROSCA members send $29.3 \%$ more than non-ROSCA members, but the duration of ROSCA membership is statistically insignificant. This suggests that ROSCA membership is more likely to be a selection effect than a treatment effect. Education also has large, positive and statistically significant effect: those with a primary school leaving certificate send $43.2 \%$ more on average. Finally, having lived in the other village is associated with an $18.5 \%$ increase in transfers.

Our key questions relate to the effect of social distance on trust. We analyse this question in Column (2), by adding a dummy variable for cases in which the Sender and Recipient are from the same village. This variable is statistically significant at the one percent level, and the point estimate on the coefficient suggests that players send $15.7 \%$ more money when paired with someone from the same village, holding all else constant. Trust does diminish somewhat with social distance.

One of the questions Senders were asked in the questionnaire was how much money they expected to get back. In Column (3) we add a variable measuring this as a proportion of the tripled amount sent. The variable is positive and statistically significant, indicating that the response to the survey is - to some extent at least - an accurate reflection of intentions.

To explore whether Trust Game donations are motivated, at least in part, by unconditional kindness, we add Triple Dictator Game donations (measured as a proportion of the endowment) as a control variable in Column (4). This variable is measured as the proportion of the endowment transferred in the Triple Dictator Game. The corresponding regression coefficient is positive and statistically significant. At the same time, the coefficient on the same-village dummy falls from $15.7 \%$ to $10.4 \%$; therefore, around one third of the social distance effect in 
the Trust Game is due to greater unconditional kindness to fellow villagers. Note also that players who send $1 \%$ more in the Triple Dictator Game send $1.5 \%$ more in the Trust Game, on average. That this number is significantly greater than $1 \%$ implies that people behaving more kindly also exhibit more pure trust. If kinder people were equally trusting then we would see a more moderate fall in the coefficient on the same-village dummy.

Risk Game investments are included in Column (5) to test whether Trust Game donations can be partly explained by the players' degree of risk aversion. This variable is statistically insignificant, suggesting that attitudes to risk do not explain why some people send more money than others in the Trust Game. This result is in contrast to Schechter (2007), who finds a strong correlation between Trust Game donations and risk, based on a sample of non-students in Paraguay. However, our result is consistent with that of Ashraf et al. (2006) and Eckel and Wilson (2004), who use a different Risk Game to ours. In Columns (3)-(5) expected returns, Triple Dictator Game donations and investments in the Risk Game are included one at a time. In Column (6) we include all of these variables in the same regression equation, and obtain results which are qualitatively similar to those reported in Columns (3)-(5). The results presented in Columns (4)-(6) indicate that both pure trust and unconditional kindness, but not risk aversion, explain the amount transferred in the Trust Game. This means that caution needs to be exercised when interpreting data from Trust Games that do not include experimental controls for other possible motives for transferring money.

Note also that when we control for Triple Dictator Game donations, the point estimates on education and ROSCA membership fall substantially, although the variables retain their statistical significance. This suggests that more educated people, and people who belong to ROSCAs, send more money not just because they are more trusting, but because they are more generous. This hypothesis is tested more directly below when we analyse the determinants of Triple Dictator Game donations.

Column (7) analyses whether players' stated reasons for transferring money are correlated with the amount sent by including dummy variables for the fairness, need and trust motives (the omitted category is the equality motive). All three of these dummy variables are positive and statistically significant. The largest point estimate on these dummies $(0.49)$ is for those stating trust as a 
motive. The gender and ROSCA membership variables become statistically insignificant once we control for motives. It is important to emphasise this does not imply gender and ROSCA membership have no role in explaining Trust Game donations, but rather stated motives capture the same underlying personal attitudes as gender and ROSCA membership.

\subsubsection{Proportions returned in the Trust Game}

We now analyse the determinants of the proportion of money returned in the Trust Game by the B Players. The results are reported in Table 3, with our baseline regression reported in Column (1). (These are Poisson regression results, because the over-dispersion coefficients in the corresponding Negative Binomial regressions are statistically insignificant.) Note that the interaction term between the dummy variable for whether the participant has ever lived in the other village and the dummy variable for participants playing with someone from the other village is excluded from the reported regressions because of collinearity. The only significant variable is the level of education. In Column (2) we add the logarithm of the amount sent. This variable is positive and statistically significant, implying that B Players are more likely to return a higher proportion of the money when the A Player gives them more to begin with. In Column (3) we add the dummy variable for whether players are from the same village, and find that this makes no difference to the proportion of money returned. Although social distance matters for trust, it appears not to make any significant difference to reciprocity.

\section{[Table 3 about here]}

Standard Dictator Game donations are added in Column (4), to test whether the proportion returned depends not just on reciprocity, but on unconditional kindness. This variable is statistically insignificant, suggesting that the proportion returned in the Trust Game is measuring pure trustworthiness or reciprocity, rather than unconditional kindness. This result contrasts with Holm and Danielson (2005), Ashraf et al. (2006) and Carter and Castillo (2003) who found that Dictator Game donations were correlated with the amount returned in the Trust Game. 
The different motives for returning money are added in Column (5). The fairness variable is statistically insignificant. The need and rewarding trust variables are both statistically significant, but have a negative sign. Those stating they returned money to reward trust returned substantially more money than those stating the need motive, but less than those stating the equality motive (the omitted category). Across the different specifications, several variables that were significant in explaining the amount of money sent by the A Players are insignificant when it comes to explaining the proportion returned by the $\mathrm{B}$ Players. Such variables include gender, years lived in the village and ROSCA membership.

\subsubsection{Dictator and Risk Game behavior}

As well as analysing whether behavior in the Dictator and Risk Games is correlated with behavior in the Trust Game, it is also of interest to test whether any of the control variables included in Tables 2 and 3 explain behavior in the Dictator Games or the Risk Game. Table 4 presents some relevant evidence in the form of regressions for the amount sent in the Dictator Games and the amount invested in the Risk Game. Recall that the Triple Dictator Game and Risk Game were played by A Players (Senders in the Trust Game) and the Dictator Game played by B Players (Recipients in the Trust Game).

\section{[Table 4 about here]}

Only two variables are statistically significant in explaining Triple Dictator Game donations. Players paired with those from the same village sent $11.4 \%$ more than those paired with players from the other village, suggesting people are more likely to be generous towards those from their own village. Those with a primary school leaving certificate were also likely to transfer more in the Triple Dictator Game, and this partly explains the fact that educated people sent more in the Trust Game. Interestingly, gender is insignificant: the fact that men send less in the Trust Game cannot be explained by lower levels of generosity. The results for the Dictator Game are reported in Column (2). Here, players transferred 3.8\% more money when paired with someone from the same village. Social distance matters to a small extent, but not as much as in the Trust and Triple Dictator Games. Other statistically significant results are that more educated and older people transferred 
more, as did those with higher incomes. Those who have never been married transferred more than those who are married, with those who are divorced transferring the least.

The results for the Risk Game are reported in Column (3). Only three variables are significant. Widows are more likely to take risks than are those who are married, and those who have lived in the village longer take fewer risks. Although ROSCA membership is insignificant, the number of years someone has been in a ROSCA is positively correlated with risk taking. If this result is taken at face value it has important policy implications, as it suggests that the longer someone is in a ROSCA the more likely they are to invest in projects entailing a degree or risk. Hence, ROSCA membership may encourage entrepreneurial behavior. Education, which has been significant in explaining behavior in most of the other games, is statistically insignificant. It is also interesting to note that gender is insignificant in explaining attitudes to risk, given that it is sometimes argued that women may send less money in the Trust Game because they are more risk averse (for example Schechter, 2007).

\section{Conclusion}

The key aim of this paper is to test what effect social distance has on experimental trust. Although not the first study to analyse this question, ours is the first to analyse whether people from a rural community are more trusting of people who live in the same village than they are of people who live in a neighbouring village. We find that trust does diminish with social distance thus defined. However, the level of trust in people from the neighbouring village is still quite high.

The money sent in the Trust Game is motivated not just by pure trust, but also partly by unconditional kindness. In Triple Dictator Game results for Senders from the Trust Game, the amount sent is roughly two thirds of the amount sent in the Trust Game, on average. Moreover, the estimated effect of social distance on the amount sent in the Trust Game falls by one third when we include the Triple Dictator Game donations in the regression for Trust Game donations. Part of the explanation for sending more money to fellow villagers in the Trust Game is that there is more generosity towards fellow villagers, on average. The regression coefficient on Triple Dictator Game donations implies that people behaving more kindly are also significantly more trusting: the amount they send in the Trust 
Game is higher not only because of their generosity, but also because they are more prepared to trust the Recipient. By contrast, the degree of risk aversion, as measured by investments in a Risk Game, is uncorrelated with the amount sent in the Trust Game.

Although we find experimental trust to decrease with social distance, trustworthiness (reciprocity) does not. Irrespective of whether B Players were paired with someone from their own village, all B Players returned at least a third of what was transferred to them. In this sense, trusting behavior is generally well rewarded.

It remains to be seen whether these characteristics of trust are replicated in other parts of Africa, in other regions which are politically stable and free of violent conflict. It also remains to be seen whether the moderate decline in villagers' trust as the radius expands to nearby villages continues at the same rate as the radius expands to the nearest town, and to further towns inhabited by people of other ethnic groups. (The success of experimental tests of such effects depends on the solution of major logistical problems.) It also remains to be seen whether there is any policy variable that can generate more trust in one's neighbour. In this regard our results concerning education are suggestive, as is our finding that geographical mobility mitigates the decline in trust as its radius increases: those few people who have ever lived in the neighbouring village in the past trust its people more today. This indicates an additional benefit of infrastructure expenditure that improves geographical mobility.

As argued by Arrow (1972), virtually all transactions require an element of trust. If people trust only those they interact with regularly, and not those they come into contact with less frequently, this will severely limit the size of the market. Our key research result from this paper is that villagers in one corner of rural Cameroon have a high degree of trust in those from their own village, and still a substantial amount of trust in those from a village with which they have limited contact. The amount of trust does fall as the radius of trust extends beyond the village, but not enormously. 


\section{References}

Arrow, K. (1972). Gifts and exchanges. Philosophy and Public Affairs, 1(4), 34362.

Ashraf, N., Bohnet, I. \& Piankov, N. (2006). Decomposing trust and trustworthiness. Experimental Economics, 9(3), 193-208.

Barr, A. (2003). Trust and expected trustworthiness: experimental evidence from Zimbabwe. Economic Journal, 113, 614-30.

Berg, J., Dickhaut, J. \& McCabe, K. (1995). Trust, reciprocity, and social history. Games and Economic Behavior, 10(1), 122-42.

Buchan, N. \& Croson, R. (2004). The boundaries of trust: own and others action in the US and China. Journal of Economic Behavior and Organization, 55, 485504.

Buchan, N., Johnson, E. \& Croson, R. (2006). Let's get personal: an international examination of the influence of communication, culture and social distance on other regarding preferences. Journal of Economic Behavior and Organization, 60, 373-98.

Cadsby, C., Song, F. \& Bi, Y. (2008). Trust, reciprocity and social distance in China: an experimental investigation. University of Guelph.

Cardenas, J. \& Carpenter, J. (2008). Behavioral development economics: lessons from field labs in the developing world. Journal of Development Studies, 44(3), 311-38.

Carter, M. \& Castillo, M. (2003). An experimental approach to social capital in South Africa. Department of Agriculture and Applied Economics, Staff Working Paper No.448, University of Wisconsin.

Chaudhuri, A. (2009). Experiments in Economics. London: Routledge.

Cox, J. (2004). How to identify trust and reciprocity. Games and Economic Behavior, 46(2), 260-81.

Eckel, C. \& Rick K. Wilson (2004). Is trust a risky decision? Journal of Economic Behavior and Organization, 55(4), 447-65.

Etang, A., Fielding, D. \& Knowles, S. (2007). Survey trust, experimental trust and ROSCA membership in rural Cameroon. Economics Discussion Paper No. 0713, University of Otago.

Fershtman, C. \& Gneezy, U. (2001). Discrimination in a segmented society - an experimental approach. Quarterly Journal of Economics, 116(1), 351-77. 
Fukuyama, F. (1995). Social capital and the global economy: a redrawn map of the world. Foreign Affairs, 74(5), 89-103.

Glaeser, L., Laibson, L., Scheinkman, A. \& Soutter, L. (2000). Measuring trust. Quarterly Journal of Economics, 11(3), 811-46.

Gourieroux, C., Monfort, A. \& Trognon, A. (1984). Pseudo maximum likelihood methods: applications to Poisson models. Econometrica, 52, 701-20.

Holm, H. \& Danielson, A. (2005). Tropic trust versus Nordic trust: experimental evidence from Tanzania and Sweden. Economic Journal, 115(503), 505-32.

Johansson-Stenman, O., Mahmud, M., \& Martinsson, P. (2006). Trust, trust games and stated trust: evidence from rural Bangladesh, Department of Economics. University of Göteborg, Working Paper No. 166.

Karlan, D. (2005). Using experimental economics to measure social capital and predict financial decisions. American Economic Review, 95(5), 1688-99.

Lyon, F. (2000). Trust, networks and norms: the creation of social capital in agricultural economies in Ghana. World Development, 28(4), 663-81.

Mosley, P. \& Verschoor, A. (2005). The development of trust and social capital in rural Uganda: an experimental approach. Working Paper 2005/011, Department of Economics, University of Sheffield.

Mullahy, J. (1986). Specification and testing of some modified count data models. Journal of Econometrics, 33, 341-65.

Netzer, R. \& Sutter, M. (2009). Intercultural trust. an experiment in Austria and Japan. Working Papers in Economics and Statistics, University of Innsbruck.

Schechter, L. (2007). Traditional trust measurement and the risk confound: an experiment in rural Paraguay. Journal of Economic Behavior and Organization, 62(2), 272-92.

Trager, L. (1981). Customers and creditors: variations in economic personalism in a Nigerian marketing system. Ethnology, 20(2), 133-46.

Walkowitz, G., Oberhammer, C. \& Henning-Schmidt, H. (2003). Experimenting over a long distance - a method to facilitate intercultural experiments. University of Bonn Discussion Paper.

Willinger, M., Keser, C., Lohmann, C. \& Usunier, J-C. (2003), A comparison of trust and reciprocity between France and Germany: experimental investigation based on the Investment Game, Journal of Economic Psychology, 24(3), 447-66. Winkelmann, R. (1997). Econometric Analysis of Count Data. Berlin: Springer. 
Table 1 Summary statistics for the sample $(N=280)$

\begin{tabular}{|c|c|c|c|}
\hline & Mean & Std. Dev. & Range \\
\hline Male (percent) & 51.8 & & \\
\hline Age (years) & 40.6 & 9.3 & {$[23,67]$} \\
\hline Never married (percent) & 5.7 & & \\
\hline Married (percent) & 87.5 & & \\
\hline Divorced (percent) & 3.2 & & \\
\hline Widow/widower (percent) & 3.6 & & \\
\hline Household size & 5.3 & 2.1 & {$[1,14]$} \\
\hline Number of children & 3.5 & 2.2 & {$[0,21]$} \\
\hline Years lived in the village & 34.5 & 12.4 & {$[6,66]$} \\
\hline Lived in an urban area (percent) & 19.6 & & \\
\hline ROSCA membership (percent) & 45.0 & & \\
\hline Duration in a ROSCA & 2.8 & 3.8 & {$[0,15]$} \\
\hline Income (million CFA francs) & 0.66 & 0.42 & {$[0.075,2]$} \\
\hline Education (percent) & 67.1 & & \\
\hline $\begin{array}{l}\text { Number of friends and/or relatives in } \\
\text { the other village }\end{array}$ & 0.3 & 1.0 & {$[0,10]$} \\
\hline Lived in the other village (percent) & 4.3 & & \\
\hline Parents divorced (percent) & 3.2 & & \\
\hline Victim of crime (percent) & 2.1 & & \\
\hline How often people visited the other & & & \\
\hline village: Very often (percent) & 1.1 & & \\
\hline Often (percent) & 14.3 & & \\
\hline Rarely (percent) & 84.6 & & \\
\hline Never (percent) & 0 & & \\
\hline
\end{tabular}


Table 2 Determinants of the amount sent ${ }^{\mathrm{a}}$

(1)

S \& R from
same village
Expected trust-
worthiness (\%)
TDG donation
$(\%)$

$\mathrm{RG}$ investment

(\%)

Male

Age

Never married

Never matried

Divorced

Household

size

Number of

children

Years lived in

village

Lived in an

urban area

ROSCA

member

Duration in a

ROSCA
(2)

0.1574

(3)

(3.15)

0.1764

(4)

(5)

(6)

(7)

$0.1037 \quad 0.1559$

0.1202

0.1060

(3.62)

(2.59)

(3.13)

(3.01)

(2.49)

0.0105

(2.15)

0.0091

(2.122)

0.0153

0.0147

(7.66)

(7.05)

$0.0008 \quad 0.0008$

(0.87) (0.98)

-0.1429
$(-2.03)$

$-0.1339$

$-0.1031$

$-0.1304$

$-0.1402$

$-0.1072$

$-0.0729$

$-0.0011-0.0022$

$(-1.76)$

(-2.16)

(-2.07)

(-2.02)

$(-1.43)$

$(-0.25) \quad(-0.55)$

$-0.0012$

$-0.0031$

$-0.0023$

$-0.0024$

$-0.0015$

$0.0867 \quad 0.0630$

$(-0.27)$

$(-0.81)$

$(-0.59)$

$(-0.56)$

(-0.39)

(1.00)

$(0.85)$

0.1198

0.0786

0.0673

0.1287

0.0736

$-0.3162 \quad-0.3571$

(1.51)

(1.02)

$(0.90)$

(1.64)

(1.34)

$(-1.94)$

(-2.39)

$-0.3114$

$-0.2652$

$-0.3582$

$-0.2358$

$-0.3746$

$0.0688 \quad 0.0477$

(-1.66)

(-2.81)

(-2.44)

(-1.92)

(-2.56)

(0.38)

(0.28)

0.0140

0.0303

0.0374

$-0.0068$

$-0.0188$

$-0.0072 \quad-0.0067$

(0.09)

(0.28)

$(0.22)$

$(-0.07)$

$(-0.12)$

$(-0.34) \quad(-0.32)$

$-0.0005$

$-0.0066$

0.0052

0.0036

$(-0.01)$

$(-0.03)$

$(-0.31)$

(0.30)

(0.22)

$\begin{array}{ll}-0.0281 & -0.025\end{array}$

$-0.0256$

$-0.0144$

$-0.0237$

$-0.0132$

$-0.0181$

$(-1.04) \quad(-0.97)$

$(-1.05)$

$(-0.69)$

$(-0.90)$

$(-0.64)$

$(-0.80)$

$\begin{array}{lll}0.0079 & 0.0079 & 0.0063\end{array}$

0.0063

0.0083

0.0054

0.0055

(2.11)

(2.24)

(1.83)

(2.18)

(2.37)

(1.80)

(1.73)

$0.0506 \quad 0.0395$

0.0423

0.0146

0.0504

0.0258

0.0074

(0.61)

(0.49)

(0.53)

$(0.22)$

(0.61)

(0.39)

(0.11)

0.2933

0.2440

0.1900

0.1901

0.2476

0.1488

0.0661

(3.40) (2.80)

(2.49)

(2.56)

(2.86)

(2.32)

(0.87)

$\begin{array}{ll}-0.0109 & -0.0078\end{array}$

$-0.0053$

$-0.0068$

$-0.0090$

$-0.0058$

0.0098

(-1.08)

$(-0.80)$

$(-0.62)$

$(-0.91) \quad(-0.78)$

${ }^{\text {a }} \mathrm{S} \& \mathrm{R}=$ Sender and Recipient; TDG $=$ Triple Dictator Game; RG = Risk Game. Negative Binomial regressions; $\alpha$ is the coefficient of over-dispersion relative to a Poisson model. The dependent variable is the proportion of money sent in the Trust Game. Heteroskedasticity-robust $t$ ratios are in parentheses. 
Table 2 (continued)

\begin{tabular}{|c|c|c|c|c|c|c|c|}
\hline & (1) & (2) & (3) & (4) & (5) & (6) & (7) \\
\hline Income (10 million & 0.467 & -0.066 & -0.594 & 0.549 & -0.158 & -0.041 & -0.574 \\
\hline CFA francs) & $(0.48)$ & $(-0.07)$ & $(-0.71)$ & $(0.63)$ & $(-0.17)$ & $(-0.05)$ & $(-0.77)$ \\
\hline Education & $\begin{array}{r}0.4319 \\
(5.70)\end{array}$ & $\begin{array}{r}0.4397 \\
(6.08)\end{array}$ & $\begin{array}{r}0.4233 \\
(6.07)\end{array}$ & $\begin{array}{r}0.2970 \\
(5.15)\end{array}$ & $\begin{array}{r}0.4412 \\
(6.08)\end{array}$ & $\begin{array}{r}0.2896 \\
(5.36)\end{array}$ & $\begin{array}{r}0.2827 \\
(4.59)\end{array}$ \\
\hline $\begin{array}{l}\text { Friends in other } \\
\text { village * B from } \\
\text { other village }\end{array}$ & $\begin{array}{r}0.0053 \\
(0.16)\end{array}$ & $\begin{array}{r}0.0295 \\
(0.94)\end{array}$ & $\begin{array}{r}0.0261 \\
(0.76)\end{array}$ & $\begin{array}{r}0.0234 \\
(0.95)\end{array}$ & $\begin{array}{r}0.0264 \\
(0.85)\end{array}$ & $\begin{array}{r}0.0173 \\
(0.61)\end{array}$ & $\begin{array}{r}0.0426 \\
(1.13)\end{array}$ \\
\hline $\begin{array}{l}\text { Lived in other } \\
\text { village * B from } \\
\text { other village }\end{array}$ & $\begin{array}{r}0.1852 \\
(1.96)\end{array}$ & $\begin{array}{r}0.2143 \\
(2.52)\end{array}$ & $\begin{array}{r}0.2036 \\
(2.21)\end{array}$ & $\begin{array}{r}0.1636 \\
(2.33)\end{array}$ & $\begin{array}{r}0.2270 \\
(2.68)\end{array}$ & $\begin{array}{r}0.1696 \\
(2.08)\end{array}$ & $\begin{array}{r}0.2446 \\
(2.16)\end{array}$ \\
\hline Motive: fairness & & & & & & & $\begin{array}{r}0.1748 \\
(2.12)\end{array}$ \\
\hline Motive: need & & & & & & & $\begin{array}{r}0.1996 \\
(2.24)\end{array}$ \\
\hline Motive: trust & & & & & & & $\begin{array}{r}0.4871 \\
(6.06)\end{array}$ \\
\hline Intercept & $\begin{array}{l}3.7424 \\
(27.62)\end{array}$ & $\begin{array}{l}3.7299 \\
(29.03)\end{array}$ & $\begin{array}{r}3.2423 \\
(11.43)\end{array}$ & $\begin{array}{c}3.1889 \\
(22.81)\end{array}$ & $\begin{array}{c}3.6687 \\
(24.95)\end{array}$ & $\begin{array}{r}2.7309 \\
(10.25)\end{array}$ & $\begin{array}{c}3.6083 \\
(29.71)\end{array}$ \\
\hline Observations & 140 & 140 & 140 & 140 & 140 & 140 & 140 \\
\hline $\ln (\alpha)$ & -2.6310 & -2.7162 & -2.8514 & -3.2741 & -2.7225 & -3.4799 & -3.4307 \\
\hline $\mathrm{R}^{2}$ & 0.2831 & 0.3001 & 0.3277 & 0.3908 & 0.3015 & 0.4149 & 0.3766 \\
\hline $\begin{array}{l}\text { Over-dispersion } \\
\text { test (p-value) }\end{array}$ & 0.000 & 0.000 & 0.000 & 0.000 & 0.000 & 0.000 & 0.000 \\
\hline
\end{tabular}


Table 3 Determinants of the proportion returned ${ }^{\text {a }}$

(1) (2) (3)

(4)

(5)

$\ln ($ amount sent $)$

0.2581
$(3.81)$

0.2518

0.2477

0.2405

S \& R from same

(3.76)

(3.59)

(3.43)

village

0.0114

0.0105

0.0201

Dictator Game

$(0.65)$

$(0.57)$

donation (\%)

Male

$0.0067 \quad 0.0177$

0.0204

0.0006

(0.46)

Age

$(0.20)$

(0.60)

(0.68)

0.0222

0.0255

0.0026

0.0023

0.0021

(0.72)

(0.86)

(1.27)

(1.18)

(1.04)

0.0020

0.0016

Never married

0.0007

$-0.0010$

0.0009

(0.97)

(0.02)

$(-0.02)$

(0.02)

$-0.0044$

$-0.0099$

Divorced

0.0142

0.0087

0.0104

$(-0.10)$

$(-0.26)$

(0.49)

(0.30)

0.0164

0.0024

(0.34)

(0.47)

Widow

0.0557

0.0225

0.0257

0.0257

0.0213

$(0.86) \quad(0.36)$

(0.42)

$(0.42)$

(0.36)

Household size

$-0.0023$

$-0.0003$

0.0002

0.0002

$-0.0003$

Number of children

$(-0.53)$

$(-0.07)$

(0.05)

(0.04)

$(-0.08)$

$-0.0086$

$-0.0082$

$-0.0085$

$-0.0085$

$-0.0089$

$(-1.38)$

$(-1.24)$

$(-1.30)$

$(-1.30)$

$(-1.33)$

Years lived in

0.0010

0.0003

0.0005

0.0006

0.0007

village

$(0.72)$

(0.25)

(0.37)

$(0.42)$

(0.52)

Lived in an urban

0.0007

0.0074

0.0097

0.0104

0.0098

area

(0.02)

(0.25)

(0.32)

(0.34)

(0.32)

ROSCA member

$-0.0034$

$-0.0005$

0.0013

0.0005

$-0.0037$

Duration in a

$(-0.11)$

$(-0.02)$

$(0.05)$

(0.02)

$(-0.13)$

0.0028

0.0026

0.0026

0.0026

0.0043

ROSCA

(0.68)

(0.66)

(0.66)

(0.65)

(1.06)

Income (10 million

$-0.232$

$-0.254$

$-0.281$

$-0.312$

$-0.286$

CFA francs)

$(-0.61)$

$(-0.79)$

$(-0.86)$

$(-0.96)$

$(-0.87)$

Education

$\mathbf{0 . 0 4 7 5} 0.0353$

0.0351

0.0313

0.0270

(2.38)

(1.88)

(1.86)

(1.67)

\footnotetext{
${ }^{a} \mathrm{~S} \& \mathrm{R}=$ Sender and Recipient. Poisson regressions. The dependent variable is the proportion of money returned in the Trust Game. Heteroskedasticity-robust t ratios are in parentheses.
} 
Table 3 (continued)

\begin{tabular}{|c|c|c|c|c|c|}
\hline & (1) & (2) & (3) & (4) & $(5)$ \\
\hline Friends in other & -0.0177 & -0.0040 & -0.0028 & -0.0022 & -0.0042 \\
\hline village $* \mathrm{~B}$ from & $(-1.26)$ & $(-0.34)$ & $(-0.23)$ & $(-0.18)$ & $(-0.34)$ \\
\hline \multicolumn{6}{|l|}{ other village } \\
\hline \multirow[t]{2}{*}{ Motive: fairness } & & & & & -0.0160 \\
\hline & & & & & $(-0.85)$ \\
\hline \multirow[t]{2}{*}{ Motive: need } & & & & & -0.2301 \\
\hline & & & & & $(-3.67)$ \\
\hline Motive: rewarding & & & & & -0.0458 \\
\hline trust & & & & & $(-1.76)$ \\
\hline \multirow[t]{2}{*}{ Intercept } & 3.7408 & 2.9411 & 2.9548 & 2.9472 & 3.0224 \\
\hline & (63.97) & (13.18) & (13.28) & (13.17) & (12.89) \\
\hline Observations & 139 & 139 & 139 & 139 & 139 \\
\hline Pseudo $\mathrm{R}^{2}$ & 0.0110 & 0.0249 & 0.0251 & 0.0252 & 0.0294 \\
\hline
\end{tabular}


Table 4 Determinants of behavior in the Triple Dictator, Dictator and Risk Games $^{\text {a }}$

(1) Triple Dictator Game

Dictator and receiver

from the same village

Male

Age

Never married

Never matied

Divorced

Widow

Household size

Number of children

Years lived in village

Lived in an urban area

ROSCA member

Duration in a ROSCA

Income (10 million

CFA francs)

Education

\subsection{7}

0.0183

$(0.29)$

0.0002

$(0.05)$

$-0.0162$

$(-0.17)$

$-0.2571$

$(-1.04)$

0.0116

(0.07)

$-0.0054$

$(-0.26)$

$-0.0334$

$(-1.21)$

0.0034

(0.90)

0.0826

(1.04)

0.0543

(0.71)

0.0020

(0.26)

$-1.03$

$(-1.28)$

0.2753

(3.35)
(2) Dictator Game

0.0387

(1.72)

$-0.0691$

$(-1.51)$

0.0045

(1.85)

0.1923

(3.16)

$-0.2550$

(-2.52)

0.0234

(0.34)

0.0014

(0.20)

$-0.0016$

$(-0.35)$

$-0.0018$

$(-1.21)$

$-0.0292$

$(-0.78)$

0.0333

(0.69)

0.0014

(0.19)

1.10

(2.46)

0.1441

(4.41)
(3) Risk Game

0.1467

0.0020

$-0.0733$

$(-0.57)$

$-0.0146$

$(-0.12)$

0.2555

$-0.0054$

$(-0.21)$

$-0.0357$

$-0.0104$

$(-2.27)$

$-0.1891$

$-0.0961$

$(-0.79)$

0.0213

$-0.0010$

$(-0.01)$

a Columns 1 and 3 are Negative Binomial regressions (where $\alpha$ is the coefficient of overdispersion relative to a Poisson model) while Column 2 is a Poisson regression. The dependent variables are the proportion of money donated in the Triple Dictator and Dictator Games (Columns 1 and 2) and the proportion invested in the Risk Game (Column 3). Heteroskedasticity-robust $t$ ratios are in parentheses. 
Table 4 (continued)

$\begin{array}{lrrr} & \text { (1) Triple Dictator Game } & \text { (2) Dictator Game } & \text { (3) Risk Game } \\ \text { Friends in other } & 0.0222 & \mathbf{- 0 . 0 3 0 6} & \\ \text { village * B from } & (0.89) & \mathbf{( - 2 . 0 8 )} & \\ \text { other village } & & & \\ \text { Lived in other village } & 0.0531 & & \mathbf{4 . 3 9 3 1} \\ * \text { B from other village } & (0.75) & \mathbf{3 . 4 9 7 6} & \mathbf{( 2 0 . 0 0 )} \\ \text { Intercept } & \mathbf{3 . 5 3 4 3} & \mathbf{( 4 6 . 0 7 )} & \\ & \mathbf{( 2 6 . 7 6 )} & & 140 \\ \text { Observations } & & & \mathbf{1 4 0} \\ \ln (\alpha) & 140 & & -1.6240 \\ \mathrm{R}^{2} & -2.5957 & 0.0697 & 0.0535 \\ \text { Over-dispersion test } & 0.0898 & & 0.000\end{array}$

(p-value) 


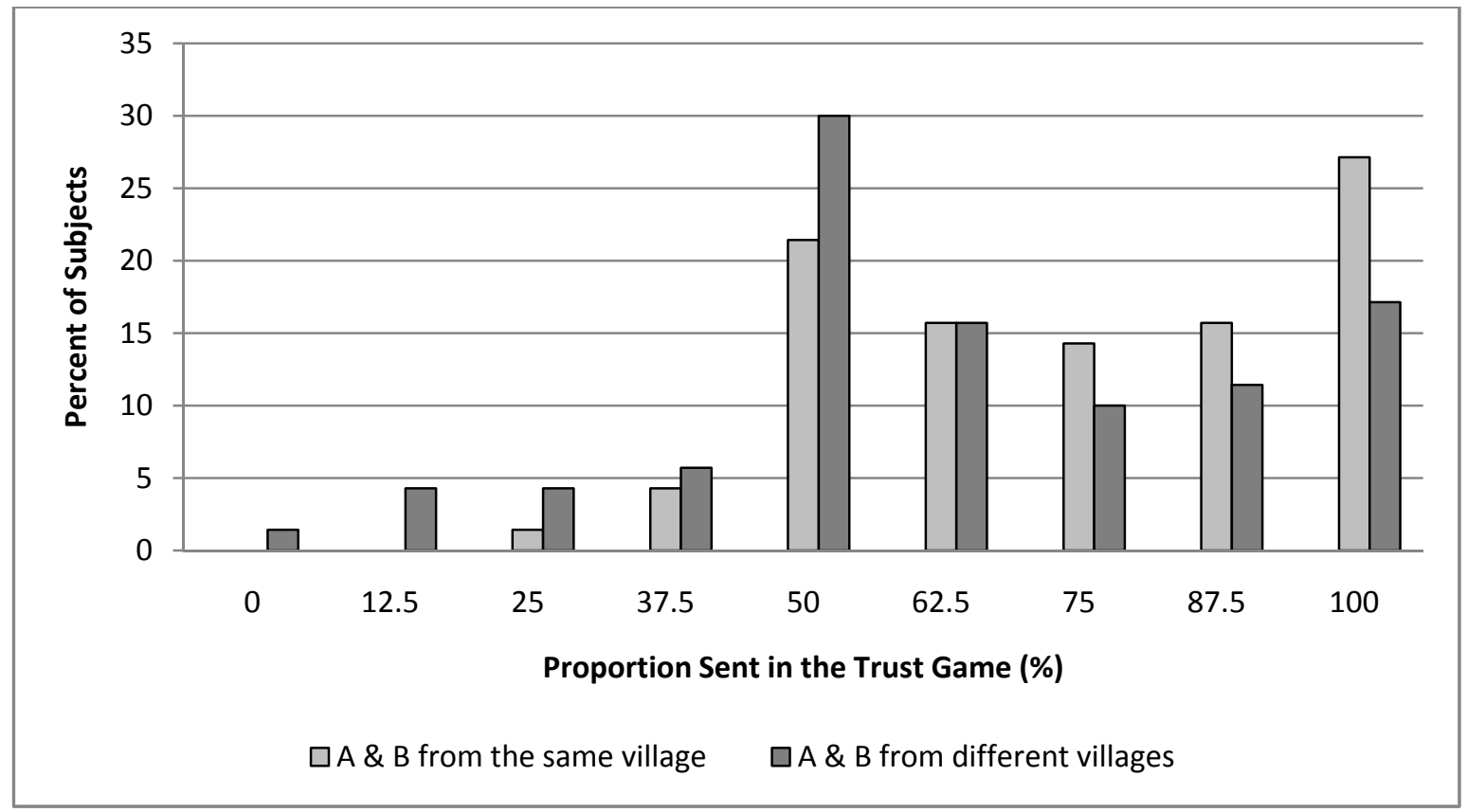

Fig. 1 Distribution of the senders' choices in the Trust Game 


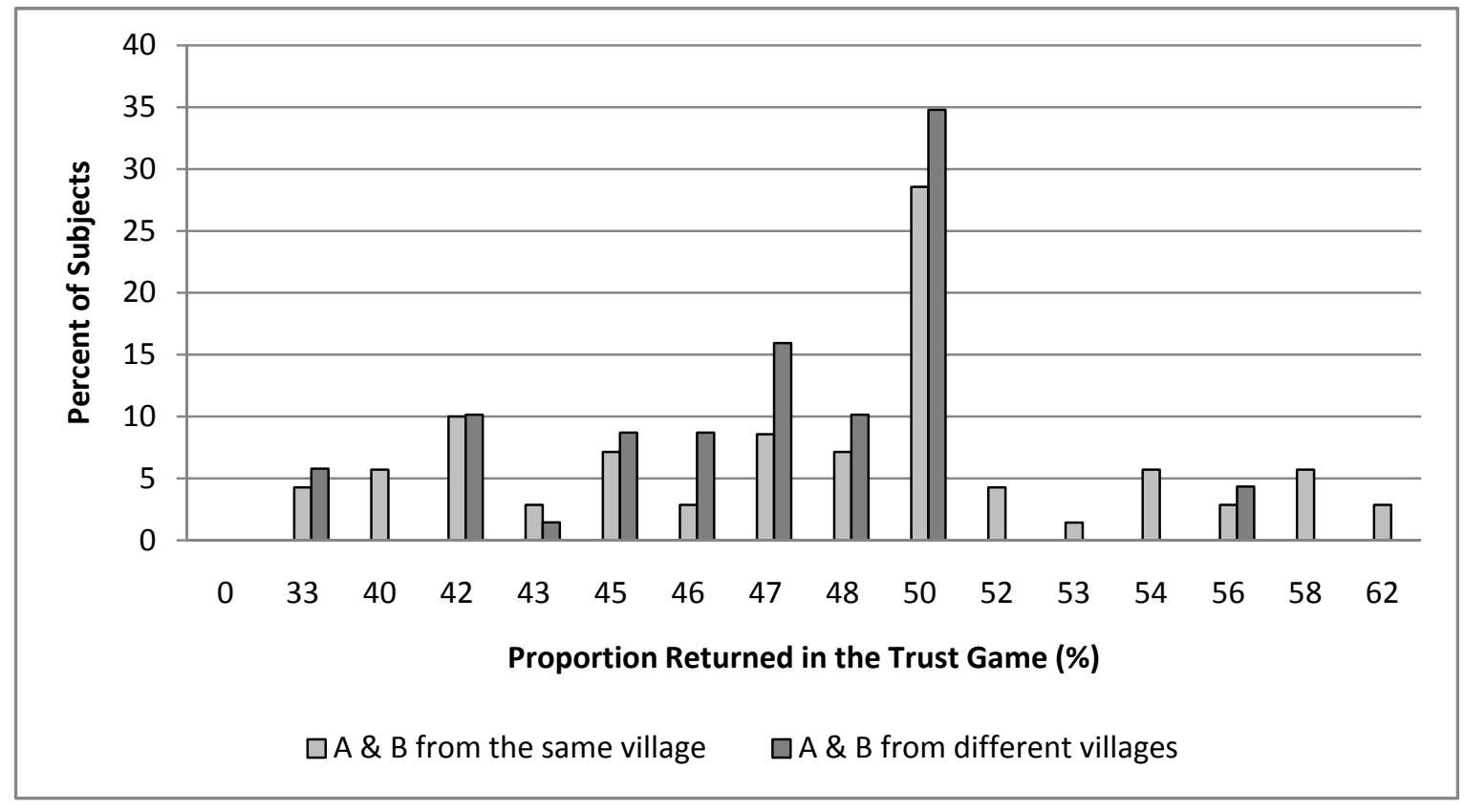

Fig. 2 Distribution of the recipients' choices in the Trust Game 


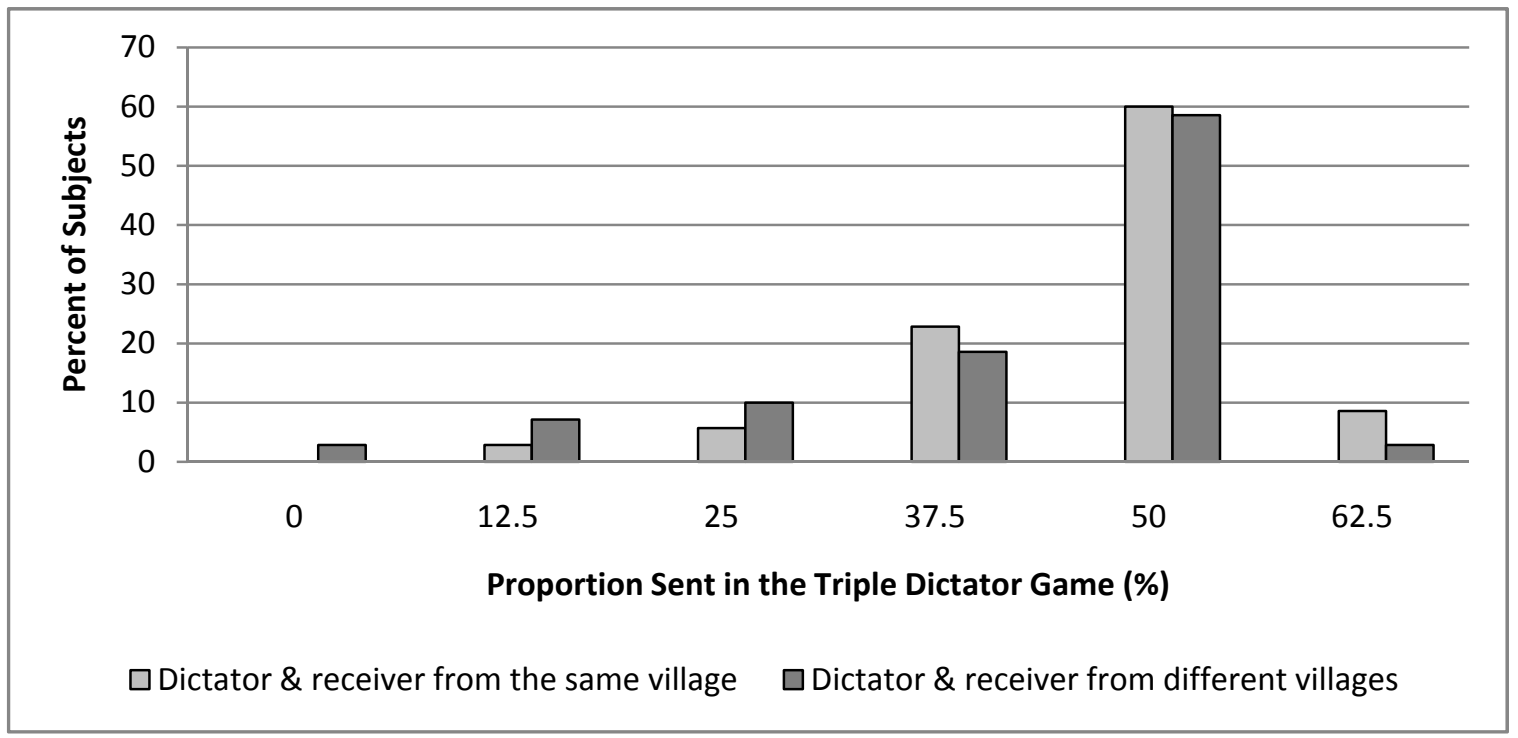

Fig. 3 Distribution of choices in the Triple Dictator Game 


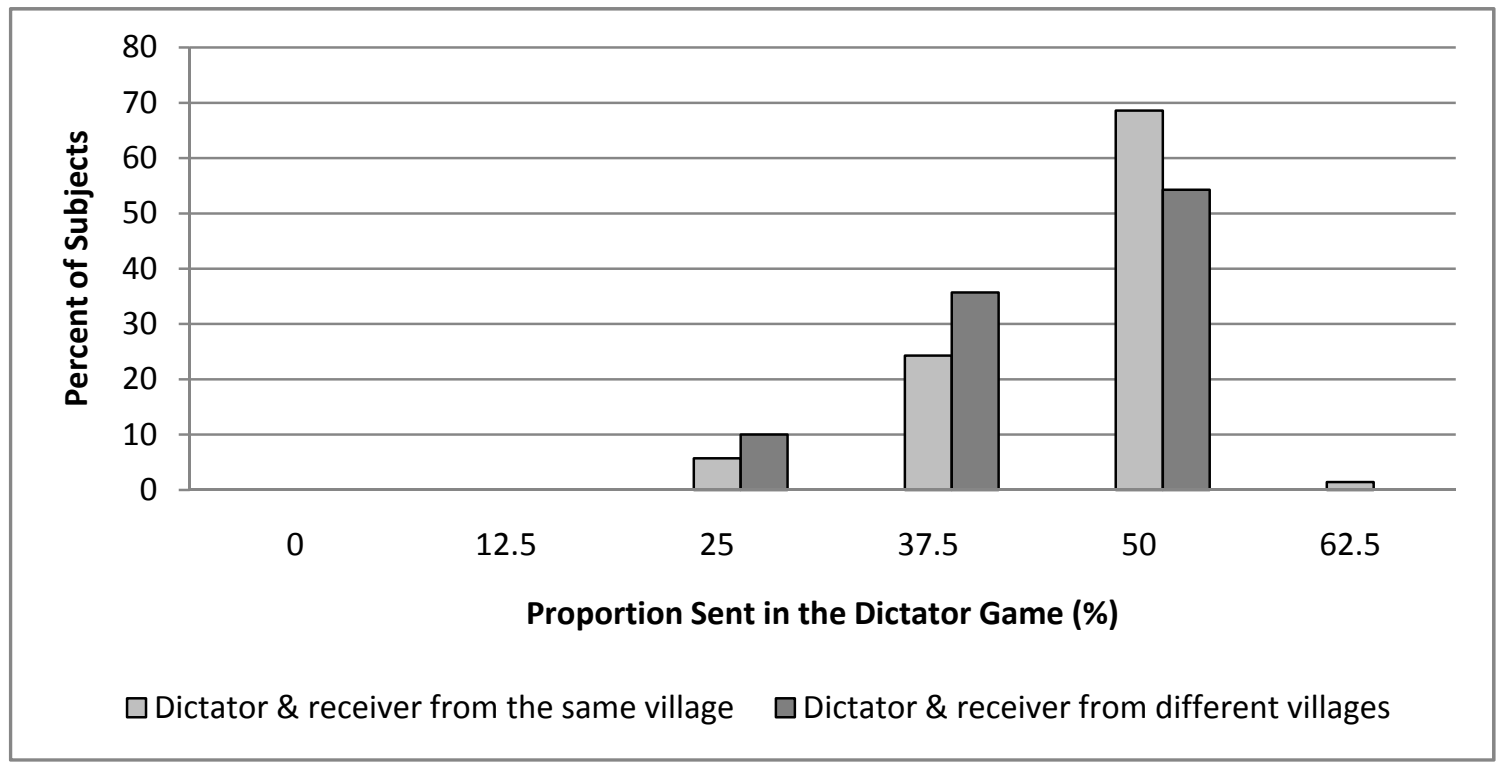

Fig. 4 Distribution of choices in the Dictator Game 


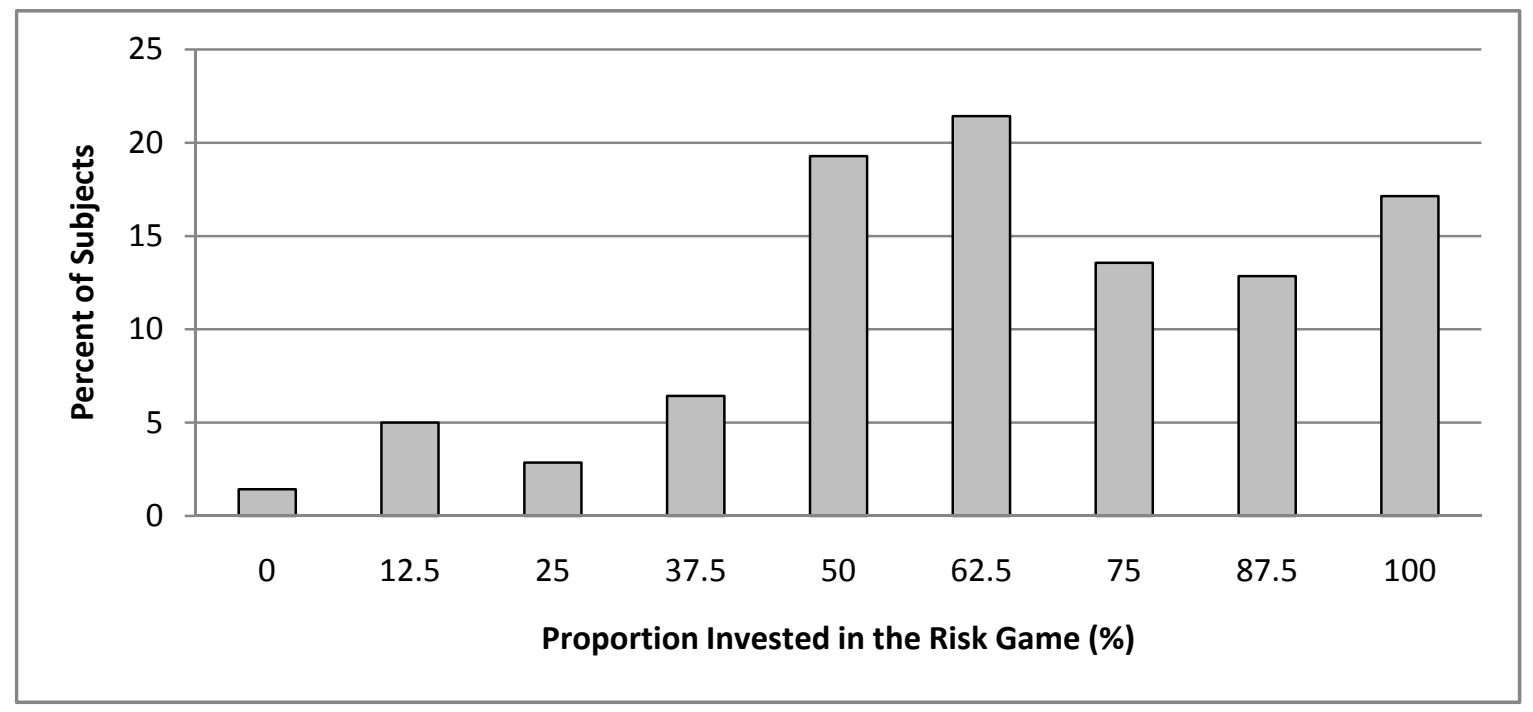

Fig. 5 Distribution of choices in the Risk Game 